\title{
Replacement Effects of Sedentary Time on Metabolic Outcomes
}

Citation for published version (APA):

Van Der Berg, J. D., Van Der Velde, J. P. M., De Waard, E. A. C., Bosma, H., Savelberg, H. H. C. M., Schaper, N. C., Van Den Bergh, J. P. W., Geusens, P. P. M. M., Schram, M. T., Sep, S. J. S., Van Der Kallen, C. J. H., Henry, R. A., Dagnelie, P. C., Eussen, S. J. P. M., Van Dongen, M. C. J. M., Kohler, S., Kroon, A. A., Stehouwer, C. D. A., \& Koster, A. (2017). Replacement Effects of Sedentary Time on Metabolic Outcomes: The Maastricht Study. Medicine and Science in Sports and Exercise, 49(7), 13511358. https://doi.org/10.1249/MSS.0000000000001248

Document status and date:

Published: 01/07/2017

DOI:

10.1249/MSS.0000000000001248

Document Version:

Publisher's PDF, also known as Version of record

Document license:

Taverne

Please check the document version of this publication:

- A submitted manuscript is the version of the article upon submission and before peer-review. There can be important differences between the submitted version and the official published version of record.

People interested in the research are advised to contact the author for the final version of the publication, or visit the DOI to the publisher's website.

- The final author version and the galley proof are versions of the publication after peer review.

- The final published version features the final layout of the paper including the volume, issue and page numbers.

Link to publication

\footnotetext{
General rights Owners
rights.

- You may freely distribute the URL identifying the publication in the public portal. please follow below link for the End User Agreement:

www.umlib.nl/taverne-license

Take down policy

If you believe that this document breaches copyright please contact us at:

repository@maastrichtuniversity.nl

providing details and we will investigate your claim.
}

Copyright and moral rights for the publications made accessible in the public portal are retained by the authors and/or other copyright owners and it is a condition of accessing publications that users recognise and abide by the legal requirements associated with these

- Users may download and print one copy of any publication from the public portal for the purpose of private study or research.

- You may not further distribute the material or use it for any profit-making activity or commercial gain

If the publication is distributed under the terms of Article $25 \mathrm{fa}$ of the Dutch Copyright Act, indicated by the "Taverne" license above, 


\title{
Replacement Effects of Sedentary Time on Metabolic Outcomes: The Maastricht Study
}

\author{
JULIANNE D. VAN DER BERG ${ }^{1,2,3}$, JEROEN H. P. M. VAN DER VELDE ${ }^{4,5,6}$, ELLIS A. C. DE WAARD ${ }^{5,6}$, HANS BOSMA ${ }^{1,2}$,
} HANS H. C. M. SAVELBERG ${ }^{4,5}$, NICOLAAS C. SCHAPER ${ }^{2,6,7}$, JOOP P. W. VAN DEN BERGH ${ }^{5,6,8,9}$, PIET P. M. M. GEUSENS ${ }^{2,6,8}$, MIRANDA T. SCHRAM ${ }^{6,7}$, SIMONE J. S. SEP ${ }^{6,7}$, CARLA J. H. VAN DER KALLEN ${ }^{6,7}$, RONALD M. A. HENRY Y,7, PIETER C. DAGNELIE ${ }^{2,7,10}$, SIMONE J. P. M. EUSSEN $^{2,7,10}$, MARTIEN C. J. M. VAN DONGEN ${ }^{2,10}$, SEBASTIAN KÖHLER ${ }^{11,12}$, ABRAHAM A. KROON ${ }^{6,7}$, COEN D. A. STEHOUWER $^{6,7}$, and ANNEMARIE KOSTER ${ }^{1,2}$

${ }^{1}$ Department of Social Medicine, Maastricht University, Maastricht, THE NETHERLANDS; ${ }^{2}$ CAPHRI Care and Public Health Research Institute, Maastricht University, Maastricht, THE NETHERLANDS; ${ }^{3}$ Radboud Institute for Health Sciences, Radboud University Medical Center, Nijmegen, THE NETHERLANDS; ${ }^{4}$ Department of Human Movement Sciences, Maastricht University, Maastricht, THE NETHERLANDS; ${ }^{5}$ NUTRIM School for Nutrition and Translational Research in Metabolism, Maastricht University, Maastricht, THE NETHERLANDS; ${ }^{6}$ Department of Internal Medicine, Maastricht University Medical Center, Maastricht, THE NETHERLANDS; ${ }^{7}$ CARIM School for Cardiovascular Diseases, Maastricht University, Maastricht, THE NETHERLANDS; ${ }^{8}$ Biomedical Research Institute, University of Hasselt, Diepenbeek, BELGIUM; ${ }^{9}$ Department of Internal Medicine, VieCuri Medical Centre, Venlo, THE NETHERLANDS; ${ }^{10}$ Department of Epidemiology, Maastricht University, Maastricht, THE NETHERLANDS; ${ }^{11}$ Department of Psychiatry and Neuropsychology, Maastricht University, Maastricht, THE NETHERLANDS; and ${ }^{12}$ MHeNS School for Mental Health and Neuroscience, Maastricht University, Maastricht, THE NETHERLANDS

\begin{abstract}
VAN DER BERG, J. D., J. H. P. M. VAN DER VELDE, E. A. C. DE WAARD, H. BOSMA, H. H. C. M. SAVELBERG, N. C. SCHAPER, J. P. W. VAN DEN BERGH, P. P. M. M. GEUSENS, M. T. SCHRAM, S. J. S. SEP, C. J. H. VAN DER KALLEN, R. M. A. HENRY, P. C. DAGNELIE, S. J. P. M. EUSSEN, M. C. J. M. VAN DONGEN, S. KÖHLER, A. A. KROON, C. D. A. STEHOUWER, and A. KOSTER. Replacement Effects of Sedentary Time on Metabolic Outcomes: The Maastricht Study. Med. Sci. Sports Exerc., Vol. 49, No. 7, pp. 1351-1358, 2017. Introduction: Sedentary time has been associated with detrimental health effects, so in some countries, guidelines to reduce sedentary time have been developed. As reducing sedentary time inevitably results in more nonsedentary time, effects of this reduction may depend on the activity with which it is replaced. Purpose: This study aimed to examine associations of theoretical reallocations of sedentary time to standing or stepping with cardiometabolic outcomes and type 2 diabetes. Methods: We included 2213 participants $(51 \%$ men, mean \pm $\mathrm{SD}$ age $=60.0 \pm 8.1 \mathrm{yr}$ ) of the Maastricht Study who were asked to wear an accelerometer $24 \mathrm{~h} \cdot \mathrm{d}^{-1}$ for a week. We calculated daily sedentary, standing, and stepping time. An isotemporal substitution modeling approach was applied to examine effects on waist circumference; body mass index; cholesterol, triacylglycerol, glucose, and insulin levels; metabolic syndrome; and type 2 diabetes. Results: Replacement of sedentary time $\left(30 \mathrm{~min} \cdot \mathrm{d}^{-1}\right)$ with stepping was associated with lower odds for metabolic syndrome (odds ratio $[\mathrm{OR}]=0.72$, $95 \%$ confidence interval $[\mathrm{CI}]=0.66-0.78)$ and type 2 diabetes $(\mathrm{OR}=0.79,95 \% \mathrm{CI}=0.72-0.87)$, more favorable waist circumference $(B=$ $-1.42,95 \% \mathrm{CI}=-1.78$ to -1.06$)$, and body mass index $(B=-0.48,95 \% \mathrm{CI}=-0.62$ to -0.35$)$ and improved cholesterol, triacylglycerol, glucose, and insulin levels. Replacing sedentary time with standing was associated with lower odds for metabolic syndrome and type 2 diabetes and favorable outcomes in waist circumference, cholesterol, triacylglycerol, and insulin levels. Conclusion: Theoretical replacements of sedentary time with nonsedentary time (both standing and stepping) were associated with lower odds for metabolic syndrome, type 2 diabetes, and beneficial metabolic outcomes. These results could be important for the general population, including those who cannot meet physical activity guidelines. Consideration should be given to developing recommendations for daily reallocating sedentary time. Key Words: SEDENTARY LIFESTYLE, DIABETES MELLITUS TYPE 2, METABOLIC SYNDROME, ACCELEROMETRY, ISOTEMPORAL SUBSTITUTION MODELING
\end{abstract}

Address for correspondence: Annemarie Koster, Ph.D., Department of Social Medicine, Maastricht University, Maastricht, the Netherlands; E-mail: a.koster@maastrichtuniversity.nl.

Submitted for publication October 2016.

Accepted for publication February 2017.

Supplemental digital content is available for this article. Direct URL citations appear in the printed text and are provided in the HTML and PDF versions of this article on the journal's Web site (www.acsm-msse.org).

0195-9131/17/4907-1351/0

MEDICINE \& SCIENCE IN SPORTS \& EXERCISE ${ }_{\circledast}$

Copyright (C) 2017 by the American College of Sports Medicine

DOI: $10.1249 /$ MSS.0000000000001248 
$\mathrm{S}$ edentary behavior, which refers to any waking behavior that is characterized by an energy expenditure $\leq 1.5$ METs while in a sitting or reclining position such as watching TV or using the computer (24), has been associated with several adverse health outcomes, including cardiometabolic risk factors (e.g., waist circumference, cholesterol and triacylglycerol levels, and insulin resistance) $(5,10)$, cardiovascular disease $(4,27)$, type 2 diabetes $(4,27)$, and premature mortality $(4,27)$.

Therefore, in some countries, health guidelines to reduce sedentary time have been developed by public health organizations and scientific institutions $(7,8)$, and the Australian government has even published a sedentary behavior guideline (2). However, specific recommendations for the amount of sedentary time that should be reduced are lacking. To develop these recommendations, studies on the health effects of reducing sedentary time are needed. More specifically, as reducing sedentary time inevitably results in larger amounts of nonsedentary time, which can vary from light physical activity (LPA) to vigorous physical activity, the effects of reducing sedentary time may depend on the activity with which it is replaced. Therefore, studies examining the effects of reduced sedentary time replaced with other types of behaviors are required.

An isotemporal substitution model (ISM) can be used to examine the effects of the theoretical replacement of sedentary time by nonsedentary time, like standing or stepping (22). Previous studies that have used an ISM approach demonstrated that a theoretical replacement of sedentary time with LPA or moderate to vigorous physical activity (MVPA) was associated with favorable health outcomes, including a reduction in body mass index (BMI) $(12,14,17,18)$ and waist circumference $(6,11,12,17,18)$, and improved markers of insulin sensitivity $(6,29)$, levels of cholesterol $(6,11,14,18)$, triacylglycerol $(6,11,14,18)$, and glucose $(6,18,29)$.

Although previous studies have used accelerometry data to assess sedentary time, in most studies sedentary time was solely based on acceleration data which cannot discriminate between postures. Consequently, standing time may have been misclassified as sedentary time or vice versa $(20,21)$. Therefore, we used the activPAL accelerometer which classifies sedentary behavior (sitting or lying) using data on posture, as this has shown to be an accurate method for assessing sedentary behavior $(13,20)$.

The aim of this study was to examine the cross-sectional associations of a theoretical reallocation of sedentary behavior (sitting or lying) to standing or stepping with cardiometabolic outcomes, metabolic syndrome, and type 2 diabetes in 2213 adults $40-75$ yr old.

\section{METHODS}

\section{Study Population}

We used data from the Maastricht Study, an observational prospective population-based cohort study. The rationale and the methodology have been described previously (23).
In brief, the study focuses on the etiology, pathophysiology, complications, and comorbidities of type 2 diabetes and is characterized by an extensive phenotyping approach. Eligible participants were individuals between 40 and $75 \mathrm{yr}$ of age and living in the southern part of the Netherlands. Participants were recruited through mass media campaigns and from the municipal registries and the regional Diabetes Patient Registry via mailings. Recruitment was stratified according to known type 2 diabetes status, with an oversampling of individuals with type 2 diabetes, for reasons of efficiency. This study included cross-sectional data from 3451 participants, who completed the baseline survey between November 2010 and September 2013. The examinations of each participant were performed within a time window of 3 months. Participants with type 1 diabetes, latent autoimmune diabetes in adults, steroidinduced diabetes, or diabetes after pancreatectomy $(n=41)$ were excluded. After further successively excluding participants who did not receive an accelerometer because of logistics $(n=668)$, whose accelerometer measurement failed $(n=135)$, or who had missing data on other measures $(n=394)$, a total of 2213 participants were included in the present analyses.

The study was approved by the institutional medical ethical committee (NL31329.068.10) and the Minister of Health, Welfare and Sports of the Netherlands (permit no. 131088105234-PG). All participants gave written informed consent.

\section{Measurements}

Cardiometabolic outcomes. The following cardiometabolic outcomes were used: waist circumference, BMI, office blood pressure, HDL cholesterol, total-to-HDL cholesterol ratio, triacylglycerol, fasting glucose, $2 \mathrm{~h}$ postload glucose, $\mathrm{HbAlc}$, fasting insulin, metabolic syndrome, and type 2 diabetes.

Waist circumference, weight, and height were measured as described elsewhere (23). BMI was calculated as kilograms per square meters. Office blood pressure was determined three times on the right arm after a 10-min rest period, using a noninvasive blood pressure monitor (Omron 705IT; OMRON, Kyoto, Japan). All available measurements were used to calculate the average blood pressure. Fasting blood samples were used for laboratory assessment of total cholesterol, HDL cholesterol, triacylglycerol, glucose, $\mathrm{HbA1c}$, and insulin levels (23). Total-to-HDL cholesterol ratio was calculated by dividing total cholesterol by HDL cholesterol. To determine $2 \mathrm{~h}$ posttload glucose and glucose metabolism status, all participants (except those who use insulin) underwent a standardized 75-g oral glucose tolerance test after an overnight fast as described elsewhere (23). The metabolic syndrome was defined according to the ATPIII guidelines by the presence of three or more of the following criteria: 1) waist circumference $\geq 102 \mathrm{~cm}$ for men and $\geq 88 \mathrm{~cm}$ for women, 2) serum triacylglycerol level $\geq 1.7 \mathrm{mmol} \cdot \mathrm{L}^{-1}$, 3) $\mathrm{HDL}$ cholesterol level $<1.03 \mathrm{mmol} \cdot \mathrm{L}^{-1}$ for men and $<1.30 \mathrm{mmol} \cdot \mathrm{L}^{-1}$ for women, 4) fasting glucose level $\geq 5.6 \mathrm{mmol} \cdot \mathrm{L}^{-1}$ or use of antidiabetic medications (insulin or oral agents), or 5) systolic blood pressure $\geq 130 \mathrm{~mm}$ $\mathrm{Hg}$ and/or diastolic blood pressure $\geq 85 \mathrm{~mm} \mathrm{Hg}$, and/or use of 
antihypertensive medications (1). To determine type 2 diabetes, participants were categorized according to the World Health Organization's 2006 criteria (28), into normal glucose metabolism (NGM), impaired fasting glucose (fasting plasma glucose 6.1-6.9 $\mathrm{mmol} \cdot \mathrm{L}^{-1}$ and $2 \mathrm{~h}$ plasma glucose (after glucose load) $<7.8 \mathrm{mmol} \cdot \mathrm{L}^{-1}$ ), impaired glucose tolerance (fasting plasma glucose $<7.0 \mathrm{mmol} \cdot \mathrm{L}^{-1}$ and $2 \mathrm{~h}$ plasma glucose $\geq 7.8-11.1 \mathrm{mmol} \cdot \mathrm{L}^{-1}$ ), or type 2 diabetes (fasting plasma glucose $\geq 7.0 \mathrm{mmol} \cdot \mathrm{L}^{-1}$ or $2 \mathrm{~h}$ plasma glucose $\geq 11.1 \mathrm{mmol} \cdot \mathrm{L}^{-1}$ ). Impaired fasting glucose and impaired glucose tolerance were combined into prediabetes. Participants on diabetes medication and without the diagnosis of type 1 diabetes were also considered to have type 2 diabetes. For the analyses with type 2 diabetes as outcome measure, we used the categories: having type 2 diabetes and not having type 2 diabetes (NGM and prediabetes).

Accelerometry data. Daily activity levels were measured using the activPAL3 ${ }^{\mathrm{TM}}$ physical activity monitor (PAL Technologies, Glasgow, UK), as described elsewhere (26). Participants were asked to wear the accelerometer for eight consecutive days, without removing it at any time. Data from the first day were excluded from the analysis because participants performed physical function tests at the research center after the device was attached. In addition, data from the final wear day providing $\leq 14$ waking hours of data were excluded from the analysis. Participants were included if they provided at least one valid day ( $\geq 10 \mathrm{~h}$ of waking data).

The total amount of sedentary time was based on the sedentary posture (sitting or lying) and calculated as the mean time spent in a sedentary position during waking time per day. The method used to determine waking time has been described elsewhere (26). The total amount of standing time was based on the standing posture and calculated as the mean time spent standing during waking time per day. The total amount of stepping was based on the stepping posture and calculated as the mean time stepping during waking time per day.

Covariates. Covariates, which were extracted from a questionnaire, included sex, age, level of education, smoking status, alcohol consumption, energy intake, mobility limitation, and prevalent cardiovascular disease. Level of education was categorized into low, medium, and high, and smoking status was categorized into never, former, and current smoker. Alcohol consumption was categorized into nonconsumers, low consumers $(\leq 7$ glasses per week for women and $\leq 14$ glasses per week for men), and high consumers ( $>7$ glasses per week for women and $>14$ glasses per week for men). Energy intake was obtained from a food frequency questionnaire and calculated as the mean energy intake (kcal) per day. Mobility limitation was obtained from the 36-Item Short Form Health Survey questionnaire and was defined as having difficulty walking $500 \mathrm{~m}$ or climbing the stairs. Prevalent cardiovascular disease was defined as a self-reported history of myocardial infarction, cerebrovascular infarction or hemorrhage, or percutaneous artery angioplasty of, or vascular surgery on, the coronary, abdominal, peripheral, or carotid arteries. The use of lipid-modifying, antihypertensive, and glucose-lowering medication was assessed during a medication interview. Depression was assessed by the structured Mini-International Neuropsychiatric Interview (25). Lastly, glucose metabolism status (using the categories NGM, prediabetes, and type 2 diabetes) was used as a covariate in all analyses except those with metabolic syndrome and type 2 diabetes.

\section{Statistical Analysis}

Characteristics of the total study population and according to sex-specific tertiles (to obtain equal distributions of men and women) of sedentary time were summarized as mean \pm SD or as numbers and percentages. The variables total-to-HDL cholesterol ratio, triacylglycerol, fasting glucose, 2 -h postload glucose, fasting insulin, and $\mathrm{HbA} 1 \mathrm{c}$ had a skewed distribution and were described using the median and the interquartile range. For the analyses, these variables were transformed using natural logarithm.

Associations of sedentary time, standing, and stepping (all expressed per 30 min by dividing total time in minutes by 30 ) with the cardiometabolic outcomes were examined for each type of behavior and each outcome separately, using linear regression analysis for the continuous variables and logistic regression analysis for metabolic syndrome and type 2 diabetes. The associations were adjusted for sex, age, level of education, waking time, smoking status, alcohol consumption, energy intake, mobility limitation, prevalent cardiovascular disease, depression, and antihypertensive and lipid-modifying medication (the metabolic syndrome and type 2 diabetes were not adjusted for medication use). The associations were also adjusted for glucose metabolism status to take into account the oversampling of participants with type 2 diabetes in the Maastricht Study (metabolic syndrome and type 2 diabetes were not adjusted for glucose metabolism status). Finally, all associations, except those describing waist circumference, BMI, and metabolic syndrome, also included BMI as covariate.

The ISM approach was applied to the cardiometabolic outcomes that were statistically significantly associated in the regression analyses. The ISM analysis involves a linear regression model that includes all types of behavior (sedentary, standing, and stepping) and total waking time. By dropping one type of behavior (e.g., sedentary behavior), the coefficients of another type of behavior (e.g., standing), will represent the estimated effect of replacing 30 min sedentary time with $30 \mathrm{~min}$ standing. The following estimated replacement effects were modeled: sedentary time replaced by standing and replaced by stepping and standing replaced by stepping. Because all types of behavior (with all types of intensities) were included in the models, the estimated replacement effects of the behaviors were independent of one another. We used time blocks of $30 \mathrm{~min}$ because a minimum of 30 min MVPA per day is required to meet the physical activity guidelines (19). The associations were adjusted as described before. In all analyses, the assumption of linearity was verified and multicollinearity was not indicated (variance inflating factors were $<2.5$ ). 
In additional analyses, we tested for interaction between all types of behavior (sedentary time, standing, and stepping) and glucose metabolism status. A $P$ value $<0.10$ for interaction was considered statistically significant. Further, the linear regression analyses were repeated with replacement of office blood pressure with 24-h average ambulatory blood pressure $(n=1956)$. All analyses were conducted with IBM SPSS Statistics 22.0 (IBM Corp., Armonk, NY).

\section{RESULTS}

A total of 2213 participants (51\% men) with an average age of $60.0 \pm 8.1 \mathrm{yr}$ were included. They provided on average $6.3 \pm 1.2$ valid days of accelerometry data, although most participants (57\%) provided seven valid days. Average waking time was $15.7 \pm 0.9 \mathrm{~h} \cdot \mathrm{d}^{-1}$, of which $9.4 \pm 1.7 \mathrm{~h}$ $(60 \%)$ was spent in a sedentary position. The remaining waking hours were spent standing $(4.3 \pm 1.3 \mathrm{~h} ; 27 \%)$ and stepping $(2.0 \pm 0.7 \mathrm{~h} ; 13 \%)$. Characteristics of the total study population and according to sex-specific tertiles of sedentary time are presented in Table 1.
To determine which outcome measures should be studied using the ISM approach, associations between all types of behavior and the cardiometabolic outcomes were examined separately using regression analyses. Sedentary time was, in the fully adjusted model, statistically significantly associated with a larger waist circumference, a higher BMI, a lower HDL cholesterol level, a higher total-to-HDL cholesterol ratio, a higher triacylglycerol level, 2-h postload glucose, and a higher fasting insulin level. Standing and stepping were associated with a lower waist circumference, a lower BMI, a higher HDL cholesterol level, a lower total-to-HDL cholesterol ratio, and a lower triacylglycerol level, 2-h postload glucose, and a lower fasting insulin level. No statistically significant associations were observed between any of the types of behavior and blood pressure, fasting glucose levels, and HbA1c. By contrast, all types of behavior were associated with metabolic syndrome and type 2 diabetes (see Table, Supplemental Digital Content 1 , Associations of sedentary time, standing, and stepping with cardiometabolic outcomes, http://links.lww.com/MSS/A885).

Table 2 presents the estimated effects of replacing $30 \mathrm{~min}$ of one type of behavior with another. After adjustment for confounders, a daily replacement of $30 \mathrm{~min}$ of sedentary time

TABLE 1. Characteristics of the total study population and according to sex-specific tertiles of sedentary time per day.

\begin{tabular}{|c|c|c|c|c|}
\hline & \multirow[b]{2}{*}{ Total Population $(N=2213)$} & \multicolumn{3}{|c|}{ Sex-Specific Tertiles of Mean Sedentary Time per Day } \\
\hline & & Tertile $1(n=737)$ & Tertile $2(n=739)$ & Tertile $3(n=737)$ \\
\hline Range sedentary time $\left(h \cdot d^{-1}\right)$ in men & $4.3-15.9$ & $4.3-9.3$ & $9.3-10.6$ & $10.6-15.9$ \\
\hline Range sedentary time $\left(h \cdot d^{-1}\right)$ in women & $2.5-14.4$ & $2.5-8.1$ & $8.1-9.5$ & $9.5-14.4$ \\
\hline Age $(y r)$ & $60.0 \pm 8.1$ & $59.0 \pm 8.2$ & $60.5 \pm 8.0$ & $60.6 \pm 8.1$ \\
\hline Sex $(\%$ men $)$ & 51.2 & 51.2 & 51.2 & 51.2 \\
\hline \multicolumn{5}{|l|}{ Educational level (\%) } \\
\hline Low & 32.8 & 33.9 & 32.3 & 32.0 \\
\hline Medium & 28.4 & 31.1 & 27.9 & 26.2 \\
\hline High & 38.9 & 35.0 & 39.8 & 41.8 \\
\hline Smoking status (\%current) & 12.1 & 10.3 & 9.3 & 16.6 \\
\hline Alcohol use ( $\%$ high) & 25.7 & 26.1 & 26.0 & 25.1 \\
\hline Energy intake $\left(\mathrm{kcal} \cdot \mathrm{d}^{-1}\right)$ & $2168.8 \pm 599.4$ & $2201.6 \pm 607.7$ & $2174.4 \pm 586.5$ & $2130.3 \pm 602.5$ \\
\hline Mobility limitation (\%) & 20.1 & 14.1 & 19.1 & 27.0 \\
\hline Lipid-modifying medication (\%) & 37.0 & 30.3 & 36.8 & 44.0 \\
\hline Antihypertensive medication (\%) & 40.6 & 31.3 & 40.1 & 50.3 \\
\hline Glucose-lowering medication (\%) & 22.3 & 14.8 & 19.9 & 32.3 \\
\hline Cardiovascular disease history (\%) & 16.4 & 14.2 & 16.1 & 19.0 \\
\hline Depression (\%) & 3.4 & 3.1 & 2.2 & 5.0 \\
\hline \multicolumn{5}{|l|}{ Glucose metabolism status (\%) } \\
\hline Normal & 56.5 & 64.6 & 59.4 & 45.5 \\
\hline Prediabetes & 15.4 & 15.2 & 15.6 & 15.6 \\
\hline Type 2 diabetes & 28.1 & 20.2 & 25.0 & 38.9 \\
\hline Waist circumference (cm) & $95.7 \pm 13.7$ & $92.3 \pm 12.6$ & $95.1 \pm 12.7$ & $99.6 \pm 14.8$ \\
\hline $\mathrm{BMI}\left(\mathrm{kg} \cdot \mathrm{m}^{-2}\right)$ & $27.0 \pm 4.5$ & $26.1 \pm 4.3$ & $26.9 \pm 4.1$ & $28.1 \pm 4.9$ \\
\hline Systolic blood pressure $(\mathrm{mm} \mathrm{Hg})$ & $135.1 \pm 18.1$ & $134.1 \pm 18.3$ & $135.3 \pm 17.7$ & $135.8 \pm 18.3$ \\
\hline Diastolic blood pressure $(\mathrm{mm} \mathrm{Hg})$ & $76.2 \pm 9.9$ & $75.9 \pm 10.1$ & $76.0 \pm 9.6$ & $76.6 \pm 10.1$ \\
\hline $\mathrm{HDL}$ cholesterol $\left(\mathrm{mmol} \cdot \mathrm{L}^{-1}\right)$ & $1.6 \pm 0.5$ & $1.7 \pm 0.5$ & $1.6 \pm 0.5$ & $1.4 \pm 0.5$ \\
\hline Total-to-HDL cholesterol ratio & $3.4(2.8-4.2)$ & $3.2(2.7-4.1)$ & $3.4(2.8-4.2)$ & $3.5(2.9-4.4)$ \\
\hline Triacylglycerol $\left(\mathrm{mmol} \cdot \mathrm{L}^{-1}\right)$ & $1.2(0.9-1.7)$ & $1.1(0.8-1.5)$ & $1.2(0.9-1.7)$ & $1.4(1.0-1.9)$ \\
\hline Fasting glucose $\left(\mathrm{mmol} \cdot \mathrm{L}^{-1}\right)$ & $5.5(5.1-6.6)$ & $5.4(5.0-6.1)$ & $5.5(5.1-6.4)$ & $5.8(5.2-7.2)$ \\
\hline 2-h postload glucose $\left(\mathrm{mmol} \cdot \mathrm{L}^{-1}\right)^{*}$ & $6.3(5.1-9.3)$ & $5.9(4.8-7.9)$ & $6.2(5.1-8.8)$ & $6.8(5.3-11.6)$ \\
\hline Fasting insulin $\left(\mathrm{pmol} \cdot \mathrm{L}^{-1}\right)$ & $61.3(42.5-94.3)$ & $54.7(38.7-83.0)$ & $60.4(43.9-88.4)$ & $71.6(44.9-113.2)$ \\
\hline $\mathrm{HbA} 1 \mathrm{c}\left(\mathrm{mmol} \cdot \mathrm{mol}^{-1}\right)$ & $38.0(35.0-44.0)$ & $37.0(34.5-41.0)$ & $38.0(35.0-43.0)$ & $40.0(35.0-48.0)$ \\
\hline $\mathrm{HbA} 1 \mathrm{c}(\%)$ & $5.6(5.6-6.2)$ & $5.6(5.3-5.9)$ & $5.6(5.3-6.1)$ & $5.8(5.4-6.6)$ \\
\hline Metabolic syndrome (\%) & 38.6 & 27.5 & 35.7 & 52.5 \\
\hline Valid days $(n)$ & $6.3 \pm 1.2$ & $6.2 \pm 1.3$ & $6.4 \pm 1.1$ & $6.2 \pm 1.2$ \\
\hline Waking time $\left(\mathrm{h} \cdot \mathrm{d}^{-1}\right)$ & $15.7 \pm 0.9$ & $15.6 \pm 0.9$ & $15.6 \pm 0.9$ & $16.0 \pm 0.9$ \\
\hline Sedentary time $\left(h \cdot d^{-1}\right)$ & $9.4 \pm 1.7$ & $7.7 \pm 1.0$ & $9.4 \pm 0.7$ & $11.1 \pm 1.0$ \\
\hline Standing time $\left(h \cdot d^{-1}\right)$ & $4.3 \pm 1.3$ & $5.4 \pm 1.2$ & $4.2 \pm 0.9$ & $3.3 \pm 0.9$ \\
\hline Stepping time $\left(\mathrm{h} \cdot \mathrm{d}^{-1}\right)$ & $2.0 \pm 0.7$ & $2.5 \pm 0.7$ & $2.0 \pm 0.5$ & $1.5 \pm 0.5$ \\
\hline
\end{tabular}

Data are presented as mean \pm SD or median $(25 \%-75 \%)$, unless stated otherwise.

${ }^{\star} N=2048$ in total group; $n=706$ in tertile $1 ; N=698$ in tertile $2 ; N=644$ in tertile 3. 


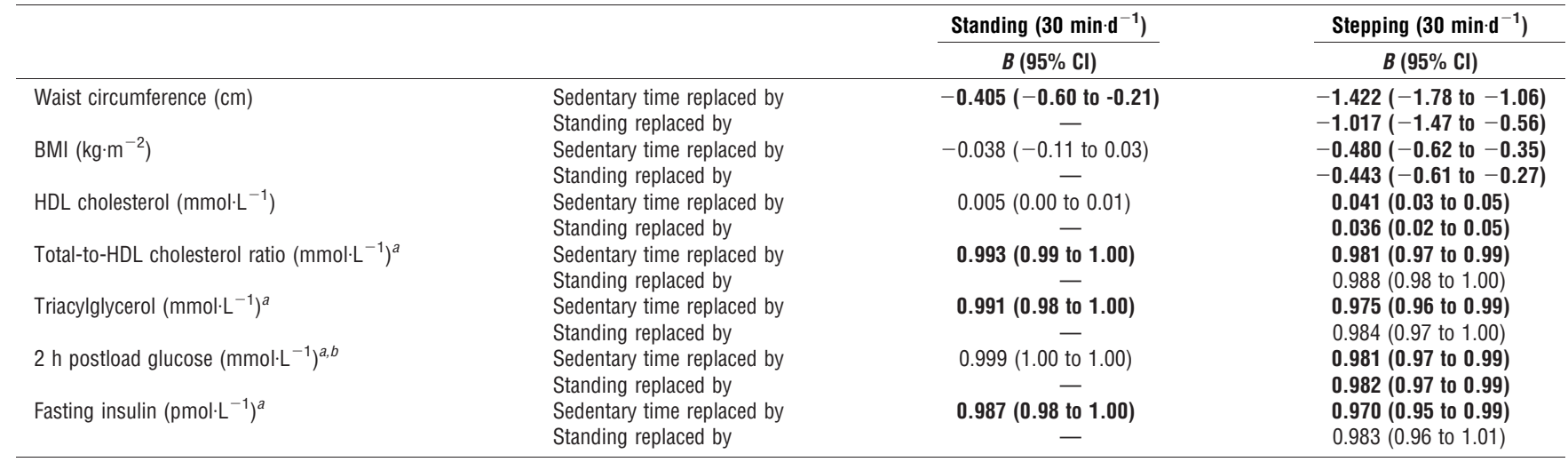

Linear regression results are presented as unstandardized coefficients $(B)$. Betas represent the estimated effect on cardiometabolic outcomes when replacing 30 min of one behavior with 30 min of another behavior. Boldface indicates statistical significance $(P<0.05)$. Associations were adjusted for sex, age, level of education, waking time, glucose metabolism status, smoking status, alcohol consumption, energy intake, mobility limitation, prevalent cardiovascular disease, depression, and antihypertensive and lipid-modifying medication. All associations except those with waist circumference and BMI were also adjusted for BMI.

${ }^{a}$ Scores are back-transformed from the natural log scale. In these cases, $B$ should be interpreted as proportional change: $B<0$ indicates negative association, $B=1$ indicates no association, and $B>1$ indicates a positive association.

${ }^{b} N=2048$.

with 30 min of standing was associated with a $0.41-\mathrm{cm}$ more favorable waist circumference ( $B_{\text {sedentary-standing }}=-0.41,95 \%$ confidence interval $[\mathrm{CI}]=-0.60$ to -0.21 ), whereas a replacement with stepping was associated with a $1.42-\mathrm{cm}$ more favorable waist circumference $\left(B_{\text {sedentary-stepping }}=-1.42\right.$, $95 \% \mathrm{CI}=-1.78$ to -1.06 ). After adjustment for confounders, associations with a more favorable BMI were seen when sedentary time was replaced by stepping $\left(B_{\text {sedentary-stepping }}=\right.$ $-0.48,95 \% \mathrm{CI}=-0.62$ to -0.35$)$, or when standing was replaced by stepping $\left(B_{\text {standing-stepping }}=-0.44,95 \% \mathrm{CI}=\right.$ -0.61 to -0.27$)$. Such replacement effects of stepping were also seen for HDL cholesterol $\left(B_{\text {sedentary-stepping }}=0.04,95 \%\right.$ $\left.\mathrm{CI}=0.03-0.05 ; B_{\text {standing-stepping }}=0.04,95 \% \mathrm{CI}=0.02-0.05\right)$, and $2 \mathrm{~h}$ postload glucose levels $\left(B_{\text {sedentary-stepping }}=0.98,95 \%\right.$ $\mathrm{CI}=0.97-0.99 ; B_{\text {standing-stepping }}=0.98,95 \% \mathrm{CI}=0.97-0.99$; back-transformed from log scale). For total-to-HDL cholesterol ratio, triacylglycerol, and fasting insulin levels, reallocating sedentary time to standing or to stepping resulted in lower totalto-HDL ratios $\left(B_{\text {sedentary-standing }}=0.99,95 \% \mathrm{CI}=0.99-1.00\right.$;
$B_{\text {sedentary-stepping }}=0.98,95 \% \mathrm{CI}=0.97-0.99$; back-transformed from log scale $)$, lower triacylglycerol levels $\left(B_{\text {sedentary-standing }}=\right.$ $0.99,95 \% \mathrm{CI}=0.98-1.00 ; B_{\text {sedentary-stepping }}=0.98,95 \% \mathrm{CI}=$ 0.96-0.99; back-transformed from log scale), and lower fasting insulin levels $\left(B_{\text {sedentary-standing }}=0.99,95 \% \mathrm{CI}=0.98-1.00\right.$; $B_{\text {sedentary-stepping }}=0.97,95 \% \mathrm{CI}=0.95-0.99$; back-transformed from log-scale).

Figure 1 presents the estimated effects on metabolic syndrome and type 2 diabetes of replacing $30 \mathrm{~min}$ of one type of behavior with another. After adjustment for confounders, associations with the metabolic syndrome were seen when sedentary time was replaced by either standing $\left(\mathrm{OR}_{\text {sedentary-standing }}=\right.$ $0.93,95 \% \mathrm{CI}=0.89-0.97)$ or stepping $\left(\mathrm{OR}_{\text {sedentary-stepping }}=\right.$ $0.72,95 \% \mathrm{CI}=0.66-0.78)$, and when standing was replaced by stepping $\left(\mathrm{OR}_{\text {standing-stepping }}=0.77,95 \% \mathrm{CI}=0.70-0.86\right)$. Similar results were seen for type 2 diabetes; after adjustment for confounders, associations were seen when sedentary time was replaced by standing $\left(\mathrm{OR}_{\text {sedentary-standing }}=0.94,95 \%\right.$ $\mathrm{CI}=0.90-0.99)$ or stepping $\left(\mathrm{OR}_{\text {sedentary-stepping }}=0.79,95 \%\right.$

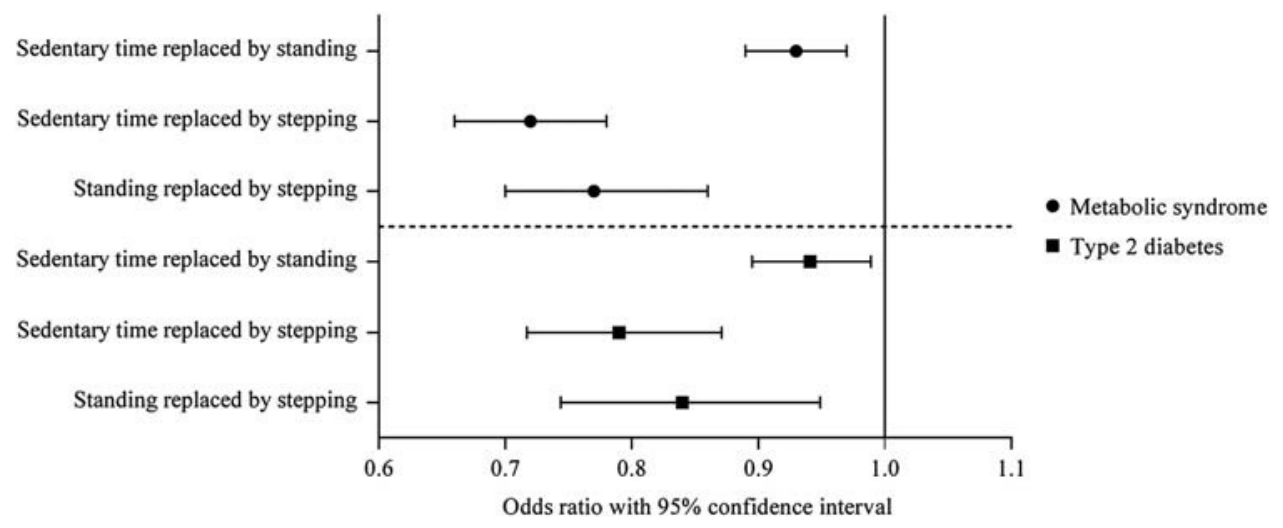

FIGURE 1-Estimated effects of replacing $30 \mathrm{~min}$ of sedentary time or standing with 30 min of standing or stepping on the metabolic syndrome and type 2 diabetes, using ISM. Odds ratios represent the odds for metabolic syndrome or type 2 diabetes when replacing 30 min of one behavior with 30 min of another behavior. Associations were adjusted for sex, age, level of education, waking time, smoking status, alcohol consumption, energy intake, mobility limitation, prevalent cardiovascular disease, and depression. Type 2 diabetes was also adjusted for BMI. 


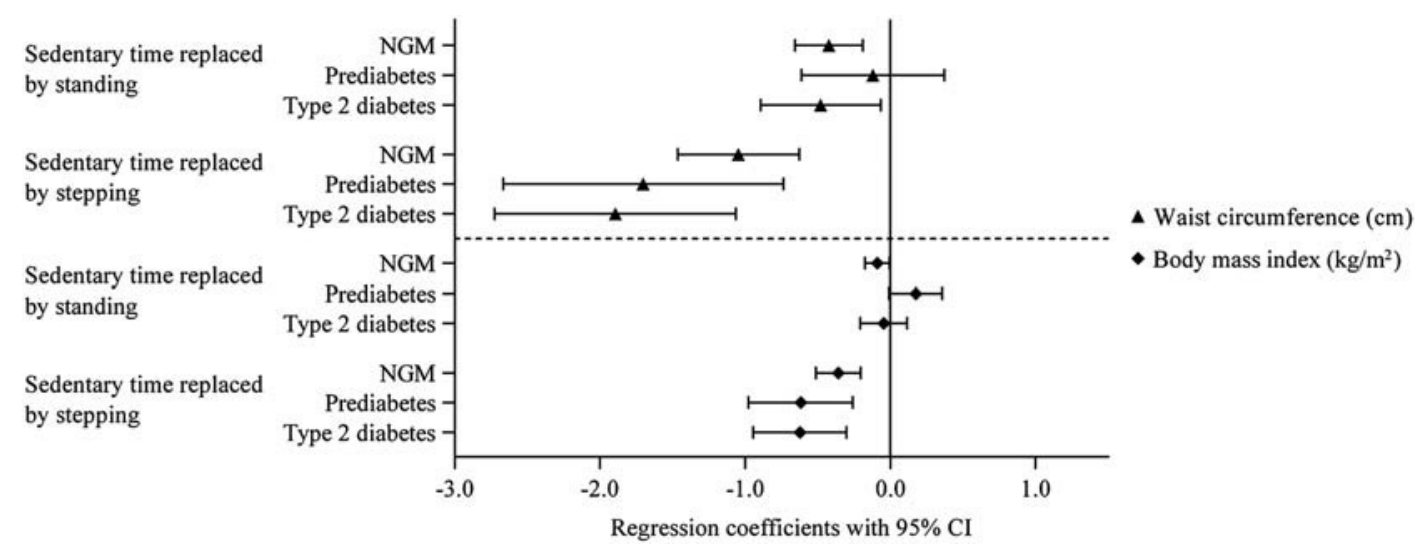

FIGURE 2-Estimated effects of replacing 30 min of sedentary time with 30 min of standing or stepping on waist circumference and BMI, according to glucose metabolism status, using ISM. Regression coefficients represent the estimated effect on waist circumference and BMI when replacing 30 min of one behavior with 30 min of another behavior. Associations were adjusted for sex, age, level of education, waking time, smoking status, alcohol consumption, energy intake, mobility limitation, prevalent cardiovascular disease, depression, and antihypertensive and lipid-modifying medication.

$\mathrm{CI}=0.72-0.87)$, and when standing was replaced by stepping $\left(\mathrm{OR}_{\text {standing-stepping }}=0.84,95 \% \mathrm{CI}=0.74-0.95\right)$.

\section{Additional Analyses}

In additional analyses, interaction terms between stepping and glucose metabolism status were statistically significant for waist circumference, BMI, and fasting insulin (all $P<$ $0.10)$. Therefore, the replacement analyses were repeated according to glucose metabolism status. Figure 2 presents the estimated effects on waist circumference and BMI of replacing $30 \mathrm{~min}$ of sedentary time with equal amounts of standing or stepping, in the NGM, prediabetes, and type 2 diabetes groups. Replacing sedentary time with standing as well as stepping was associated with a more favorable waist circumference in all groups, but larger effects were seen in the prediabetes and type 2 diabetes groups compared with the NGM group. For example, replacing sedentary time with stepping was associated with a $1.05-\mathrm{cm}$ more favorable waist circumference in the NGM group $\left(B_{\text {sedentary-stepping }}=-1.05\right.$, $95 \% \mathrm{CI}=-1.47$ to -0.63$)$, whereas this was $1.70 \mathrm{~cm}$ $\left(B_{\text {sedentary-stepping }}=-1.70,95 \% \mathrm{CI}=-2.67\right.$ to -0.74$)$ and $1.89 \mathrm{~cm}\left(B_{\text {sedentary-stepping }}=-1.89,95 \% \mathrm{CI}=-2.73\right.$ to -1.06$)$ in the prediabetes and type 2 diabetes groups, respectively. A similar pattern was seen for BMI: replacing sedentary time with stepping was associated with a $0.36-\mathrm{kg} \cdot \mathrm{m}^{-2}$ more favorable BMI in the NGM group $\left(B_{\text {sedentary-stepping }}=-0.36,95 \% \mathrm{CI}=\right.$ -0.51 to -0.20$)$, whereas this was $0.62 \mathrm{~kg} \cdot \mathrm{m}^{-2}\left(B_{\text {sedentary-stepping }}=\right.$ $-0.62,95 \% \mathrm{CI}=-0.98$ to -0.26$)$ in the prediabetes group and $0.62 \mathrm{~kg} \cdot \mathrm{m}^{-2}\left(B_{\text {sedentary-stepping }}=-0.62,95 \% \mathrm{CI}=-0.95\right.$ to -0.30 ) in the type 2 diabetes groups. Although a statistically significant interaction term was found between stepping and glucose metabolism status for fasting insulin, the replacement effects on fasting insulin in the NGM, prediabetes, and type 2 diabetes groups were similar (data not shown).

Further, in additional analyses, using 24-h average ambulatory blood pressure instead of office blood pressure resulted in similar findings; no associations were seen with any type of behavior (data not tabulated). Also, all results remained similar when we excluded participants having less than four valid days.

\section{DISCUSSION}

In this study, we used the ISM approach to estimate the effects of a theoretical reallocation of sedentary behavior (sitting or lying) to standing or stepping with cardiometabolic outcomes, metabolic syndrome, and type 2 diabetes. The results show that, after adjustment for confounders, reallocating $30 \mathrm{~min}$ of sedentary time per day to standing or stepping was significantly associated with $7 \%$ to $28 \%$ lower odds for metabolic syndrome and $6 \%$ to $21 \%$ lower odds for type 2 diabetes. Further, replacing sedentary behavior with nonsedentary behavior was beneficially associated with several metabolic outcomes. The largest estimated effects were seen when sedentary time was replaced by stepping: replacing $30 \mathrm{~min}$ sedentary time per day by stepping resulted in a 1.4-cm more favorable waist circumference, a $0.5-\mathrm{kg} \cdot \mathrm{m}^{-2}$ more favorable BMI, and improved levels of cholesterol (both HDL and total-to-HDL ratio), triacylglycerol, and 2-h postload glucose. Also, the replacement of sedentary behavior with standing was associated with a more favorable waist circumference, a lower total-to-HDL cholesterol ratio, a lower triacylglycerol level, and a lower insulin level. In addition, reducing standing by replacing it with stepping was associated with more favorable waist circumference and BMI, improved HDL cholesterol, and 2-h postload glucose levels and lower odds for metabolic syndrome and type 2 diabetes. Finally, when estimating the effects of replacing sedentary time with standing or stepping in groups according to glucose metabolism status, larger replacement effects were seen in participants with prediabetes and type 2 diabetes compared with participants with NGM for both waist circumference and BMI. However, this was likely due to the larger measures of waist circumference and BMI in the prediabetes and type 2 diabetes groups rather than glucose metabolism per se. Taken together, the results suggest that reallocating sedentary behavior, even in relatively small amounts of $30 \mathrm{~min} \cdot \mathrm{d}^{-1}$, may have favorable effects on 
metabolic outcomes, metabolic syndrome, and type 2 diabetes. Interestingly, these favorable results were not only seen when sedentary time was replaced by stepping (e.g., physical activity), but also when it was replaced by standing. Also, as stronger associations for waist circumference and BMI were seen in participants with prediabetes and type 2 diabetes, reallocation of only 30 min of sedentary time per day to standing or stepping may be clinically relevant. Thus, our results provide new insight into the potential effects of reallocating sedentary time, which may be used for health guidelines and may also give direction to experimental or intervention studies on the amounts of reallocation time that should be examined. For these reasons, our findings are relevant for the general population, for those who cannot participate in high-intensity activities, and for those who cannot meet the physical activity guidelines.

Our results are in line with findings of previous studies using the ISM approach. Most of these studies reported associations of reallocating sedentary time to LPA or MVPA with reductions in waist circumference $(6,11,12,17,18)$ and BMI $(12,14,17,18)$. Less consistent results were seen for other metabolic outcomes including levels of cholesterol, triacylglycerol, and glucose. In a few studies including ours $(11,18)$, statistically significant associations were seen with HDL cholesterol when replacing sedentary time with more active types of behavior, whereas other studies showed no associations (12) or only associations with MVPA $(6,14)$. Similar inconsistencies were seen for triacylglycerol $(6,11,14,18)$ and glucose levels $(6,11,18,29)$. These inconsistencies could be due to the study population, which varied in age (36 to $80 \mathrm{yr}$ ) and in metabolic profile (healthy participants, participants at increased risk for type 2 diabetes, and participants with type 2 diabetes). In addition, the replacement time varied between studies, as some studies used blocks of 10 min $(11,14)$, whereas we and others used 30-min blocks $(6,17,29)$, and even 2-h blocks were used (18). Further, most studies used a waistor hip-worn accelerometer, which cannot distinguish between postures. Consequently, estimations of the amount of sedentary time in these studies were less accurate than the estimates in our study, as we used a posture-based accelerometer $(13,20,21)$. In only one other study, a posture-based accelerometer was used, and the reported results were similar to ours, although in that study an allocation time of $2 \mathrm{~h}$ was used (18).

Possible pathophysiological mechanisms that may explain our findings have not yet been studied extensively. However, animal studies have described plausible mechanisms that may underlie the detrimental health effects of large amounts of sedentary time, including reductions in lipoprotein lipase and lipid phosphate phosphatase 1 , because of muscle inactivity $(15,16)$. Participation in nonsedentary behavior may be sufficient to counterbalance these processes. It has been shown that reducing inactivity by low-intensity activities, such as walking and standing, was effective in improving insulin level and plasma lipids, which supports our hypothesis (9). In addition, previous experimental and epidemiological studies have demonstrated that breaking up sedentary time with nonsedentary time had beneficial effects on metabolic outcomes, which supports also this hypothesis (3). Nevertheless, physiological studies are needed to further examine this.

The use of posture-based accelerometer was a key strength of this study, as well as the large study population consisting of adults with NGM, prediabetes, and type 2 diabetes. Another strength of this study was adjustment for a series of relevant confounders, including total energy intake. However, this could have resulted in overadjustment bias as an increase in standing or stepping could result in a higher energy intake.

A few limitations should also be mentioned. Because of the cross-sectional nature of the study, causal relationships could not be determined and reverse causality could not be excluded. Moreover, the replacement effects resulting from the ISM approach were estimated rather than based on actual behavioral reallocation. Although this method can provide valuable insights into the potential effects on health, experimental and intervention studies are warranted to examine the actual behavioral reallocation effects on both short and long term. Further, as our accelerometry data were posture based, we used total stepping time as a measure for physical activity, but different intensity levels were not determined. In addition, stepping time was not classified into higher and lower intensity stepping because the associations of lower intensity stepping with the outcome measures were nonlinear. Therefore, future studies ideally should combine posture-based data for accurate assessment of sedentary behavior with acceleration data for determining physical activity intensity levels. In addition, because of missing data, we had to exclude 1200 participants. However, the excluded participants did not differ from our study sample with regard to demographic factors, accelerometry variables, and outcomes measures (data not shown). Finally, our study population consisted of a relatively healthy population, including individuals with well-controlled type 2 diabetes; therefore, the results might not be representative for the general population of adults 40-75 $\mathrm{yr}$ of age.

To conclude, our study demonstrated that a theoretical replacement of sedentary time with standing or stepping was associated with a decreased likelihood for metabolic syndrome and type 2 diabetes, more favorable waist circumference and BMI, and improved levels of HDL cholesterol, triacylglycerol, glucose, and insulin. In addition, replacing standing with stepping was associated with an improved waist circumference, BMI, HDL cholesterol and glucose level, metabolic syndrome, and type 2 diabetes. Further, the theoretical replacement effects for both waist circumference and BMI were larger in participants with prediabetes and type 2 diabetes. As reallocating of even small amounts of sedentary behavior to any type of nonsedentary behavior seems to be beneficial for health, consideration should be given to developing health guidelines that include recommendations for the daily reallocation of sedentary time, although longitudinal and intervention studies on actual behavioral reallocation effects are needed to confirm our results.

The researchers are indebted to the participants for their willingness to participate in the study. 
This study was supported by the European Regional Development Fund via OP-Zuid, the Province of Limburg, the Dutch Ministry of Economic Affairs (grant no. 310.041), Stichting De Weijerhorst (Maastricht, the Netherlands), the Pearl String Initiative Diabetes (Amsterdam, the Netherlands), the Cardiovascular Center (CVC, Maastricht, the Netherlands), CARIM School for Cardiovascular Diseases (Maastricht, the Netherlands), CAPHRI School for Public Health and Primary Care (Maastricht, the Netherlands), NUTRIM School for Nutrition and Translational Research in Metabolism (Maastricht, the Netherlands), Stichting Annadal (Maastricht, the Netherlands), and Health Foundation Limburg (Maastricht, the Netherlands) and by unrestricted grants from

\section{REFERENCES}

1. Alberti KG, Eckel RH, Grundy SM, et al. Harmonizing the metabolic syndrome: a joint interim statement of the International Diabetes Federation Task Force on Epidemiology and Prevention; National Heart, Lung, and Blood Institute; American Heart Association; World Heart Federation; International Atherosclerosis Society; and International Association for the Study of Obesity. Circulation. 2009;120(16):1640-5.

2. Australian Government Department of Health. Australia's Physical Activity and Sedentary Behaviour Guidelines for Adults (18-64 years). 2014. [cited September 2016]. Available from: http://www.health. gov.au/internet/main/publishing.nsf/Content/phy-activity.

3. Benatti FB, Ried-Larsen M. The effects of breaking up prolonged sitting time: a review of experimental studies. Med Sci Sports Exerc. 2015;47(10):2053-61.

4. Biswas A, Oh PI, Faulkner GE, et al. Sedentary time and its association with risk for disease incidence, mortality, and hospitalization in adults: a systematic review and meta-analysis. Ann Intern Med. 2015;162(2):123-32.

5. Brocklebank LA, Falconer CL, Page AS, Perry R, Cooper AR. Accelerometer-measured sedentary time and cardiometabolic biomarkers: a systematic review. Prev Med. 2015;76:92-102.

6. Buman MP, Winkler EA, Kurka JM, et al. Reallocating time to sleep, sedentary behaviors, or active behaviors: associations with cardiovascular disease risk biomarkers, NHANES 2005-2006. Am J Epidemiol. 2013;179(3):323-34.

7. Canadian Society of Exercise Physiology. Canadian Physical Activity and Sedentary Behaviour Guidelines. 2012. [cited September 2016]. Available from: www.csep.ca/guidelines.

8. Department of Health Physical Activity Health Improvement and Protection. Start Active, Stay Active. 2011.[cited September 2016]. Available from: https://www.gov.uk/government/publications/ start-active-stay-active-a-report-on-physical-activity-from-thefour-home-countries-chief-medical-officers.

9. Duvivier BM, Schaper NC, Bremers MA, et al. Minimal intensity physical activity (standing and walking) of longer duration improves insulin action and plasma lipids more than shorter periods of moderate to vigorous exercise (cycling) in sedentary subjects when energy expenditure is comparable. PLoS One. 2013;8(2):e55542.

10. Edwardson CL, Gorely T, Davies MJ, et al. Association of sedentary behaviour with metabolic syndrome: a meta-analysis. PLoS One. 2012;7(4):e34916.

11. Ekblom-Bak E, Ekblom Ö, Bergström G, Börjesson M. Isotemporal substitution of sedentary time by physical activity of different intensities and bout lengths, and its associations with metabolic risk. Eur J Prev Cardiol. 2016;23(9):967-74.

12. Falconer CL, Page AS, Andrews RC, Cooper AR. The potential impact of displacing sedentary time in adults with type 2 diabetes. Med Sci Sports Exerc. 2015;47(10):2070-5.

13. Godfrey A, Culhane KM, Lyons GM. Comparison of the performance of the activPAL Professional physical activity logger to a discrete accelerometer-based activity monitor. Med Eng Phys. 2007;29(8):930-4.
Janssen-Cilag B.V. (Tilburg, the Netherlands), Novo Nordisk Farma B.V. (Alphen aan den Rijn, the Netherlands), and Sanofi-Aventis Netherlands B.V. (Gouda, the Netherlands). A Koster has received funding from the European Union Seventh Framework Programme (FP7-PEOPLE-2011-CIG) under grant agreement PCIG09-GA-2011293621.

The authors report no conflicts of interest relevant to this manuscript. The results of the present study do not constitute endorsement by the American College of Sports Medicine.

The authors declare that the results of the study are presented clearly, honestly, and without fabrication, falsification, or inappropriate data manipulation.

14. Hamer M, Stamatakis E, Steptoe A. Effects of substituting sedentary time with physical activity on metabolic risk. Med Sci Sports Exerc. 2014;46(10):1946-50.

15. Hamilton M, Hamilton D, Zderic T. Role of low energy expenditure and sitting in obesity, metabolic syndrome, type 2 diabetes, and cardiovascular disease. Diabetes. 2007;56:2655-67.

16. Hamilton MT, Hamilton DG, Zderic TW. Sedentary behavior as a mediator of type 2 diabetes. Med Sport Sci. 2014;60:11-26.

17. Healy GN, Winkler EA, Brakenridge CL, Reeves MM, Eakin EG. Accelerometer-derived sedentary and physical activity time in overweight/obese adults with type 2 diabetes: cross-sectional associations with cardiometabolic biomarkers. PLoS One. 2015;10:e119140.

18. Healy GN, Winkler EA, Owen N, Anuradha S, Dunstan DW. Replacing sitting time with standing or stepping: associations with cardio-metabolic risk biomarkers. Eur Heart J. 2015;36(39): 2643-9.

19. Hildebrandt H, Ooijendijk M, Hopman M. Trend Report Physical Activity and Health 2000/2014. Trendrapport Bewegen en Gezondheid 2000/2014. 2010:16.

20. Kozey-Keadle S, Libertine A, Lyden K, Staudenmayer J, Freedson PS. Validation of wearable monitors for assessing sedentary behavior. Med Sci Sports Exerc. 2011;43(8):1561-7.

21. Lyden K, Kozey Keadle SL, Staudenmayer JW, Freedson PS. Validity of two wearable monitors to estimate breaks from sedentary time. Med Sci Sports Exerc. 2012;44(11):2243-52.

22. Mekary RA, Willett WC, Hu FB, Ding EL. Isotemporal substitution paradigm for physical activity epidemiology and weight change. Am J Epidemiol. 2009;170(4):519-27.

23. Schram MT, Sep SJ, van der Kallen CJ, et al. The Maastricht Study: an extensive phenotyping study on determinants of type 2 diabetes, its complications and its comorbidities. Eur J Epidemiol. 2014;29(6):439-51.

24. Sedentary Behaviour Research Network. Letter to the editor: standardized use of the terms "sedentary" and "sedentary behaviours." Appl Physiol Nutr Metab. 2012;37:540-2.

25. Sheehan DV, Lecrubier Y, Sheehan KH, et al. The Mini-International Neuropsychiatric Interview (M.I.N.I.): the development and validation of a structured diagnostic psychiatric interview for DSM-IV and ICD-10. J Clin Psychiatry. 1998;59(20 Suppl):22-3.

26. van der Berg JD, Willems PJ, van der Velde JH, et al. Identifying waking time in 24-h accelerometry data in adults using an automated algorithm. J Sports Sci. 2016;34:1867-73.

27. Wilmot EG, Edwardson CL, Achana FA, et al. Sedentary time in adults and the association with diabetes, cardiovascular disease and death: systematic review and meta-analysis. Diabetologia. 2012;55(11):2895-905.

28. World Health Organization. Definition and Diagnosis of Diabetes Mellitus and Intermediate Hyperglycemia. 2006. 1-3.

29. Yates T, Henson J, Edwardson C, et al. Objectively measured sedentary time and associations with insulin sensitivity: importance of reallocating sedentary time to physical activity. Prev Med. 2015;76:79-83. 